\title{
Techniques to refine the upper outer breast aesthetic subunit in alloplastic breast reconstruction: The lateral capsular flap
}

\author{
Brent R DeGeorge Jr MD PhD, Christopher A Campbell MD
}

BR DeGeorge Jr, CA Campbell. Techniques to refine the upper outer breast aesthetic subunit in alloplastic breast reconstruction: The lateral capsular flap. Plast Surg 2016;24(2):83-88.

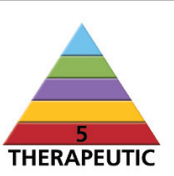

BACKGROUND: Lateral displacement of breast implants and axillary fullness are common causes of patient dissatisfaction and reoperation following prosthetic breast reconstruction. Suture plication of the capsule and acellular dermal matrix slings have been described to address lateral implant malposition, but with unacceptably high rates of recurrence and additional cost, respectively.

OBJECTIVE: To describe a novel technique using a lateral capsular flap to provide durable correction of implant malposition and, at the same time, redefinition of the lateral breast border, thereby restoring balance to the breast aesthetic subunits.

METHODS: Sixteen patients presented with lateral malposition of tissue expanders or breast implants during staged implant-based breast reconstruction, four of whom had additional unwanted axillary soft tissue fullness. An anteriorly based lateral capsular flap was performed for each breast to reconstruct the lateral border of the breast, return the implant to its appropriate position and address axillary fullness when indicated.

RESULTS: Lateral capsular flaps were performed for 16 patients (20 breasts) resulting in durable medial repositioning of the implant for a minimum of six months follow-up (range six to 60 months). Eight patients presented after implant placement with subsequent malposition while the remainder presented after tissue expander placement alone. For the eight patients with axillary fullness, elevation of the capsular flap allowed access to axillary contents for excision (four cases) or incorporation of axillary fat into the flap to prevent lateral implant palpability. No major complications, infectious complications or wound healing complications were reported. All patients showed satisfactory results, and reported high cosmetic and functional satisfaction with the appearance of their reconstructed breasts and axillary comfort.

CONCLUSIONS: In the authors' experience, the lateral capsular flap represents a simple, safe and reliable technique to correct breast implant lateral malposition, reconstruct the lateral breast border, and address unwanted axillary fullness in primary or revision implant-based breast reconstruction with improved cosmetic appearance and balance of the breast.

Key Words: Breast surgery; Breast aesthetic subunits; Capsular flap; Lateral breast border

$\mathrm{T}$ he goals of breast reconstruction continue to evolve as women become increasingly knowledgeable about breast cancer therapeutic options, including ablative and reconstructive techniques (1-3). Simply reconstructing a breast mound of adequate size and dimension to appear symmetric with the camouflage of undergarments and clothing is no longer sufficient (4-6). Knowledgeable patients and surgeons expect to achieve natural-appearing and attractive breasts with reasonable symmetry, contour and projection without clothing $(2,3,7)$. To achieve these goals, the breast surgeon and plastic surgeon must work in concert to plan the ablative and reconstructive procedures using aesthetic subunit principles to minimize visible scars and restore the breast mound to a normal and natural shape.

\author{
Des techniques pour améliorer la sous-unité \\ esthétique du quadrant supéro-externe du sein en \\ cas de reconstruction mammaire alloplastique : le \\ lambeau capsulaire latéral
} HISTORIQUE : Le déplacement latéral des implants mammaires et de la
plénitude axillaire sont des causes courantes d'insatisfaction des patientes
et de réopération après une reconstruction mammaire prosthétique. La
plication de la suture de la capsule et les attelles de la matrice dermique
acellulaire corrigent la malposition latérale des implants, mais s'associent
à un taux inacceptable de récurrence et à des coûts supplémentaires,
respectivement.

OBJECTIF : Décrire une technique novatrice au moyen d'un lambeau capsulaire latéral afin de corriger durablement la malposition de l'implant tout en redéfinissant la limite latérale du sein, afin de restaurer l'équilibre des sous-unités esthétiques du sein.

MÉTHODOLOGIE : Seize patientes ont consulté en raison d'une malposition latérale des expanseurs tissulaires ou des implants mammaires pendant la reconstruction mammaire graduelle par implants, dont quatre présentaient une plénitude indésirable des tissus mous axillaires. Elles ont reçu un lambeau capsulaire latéral antérieur pour chaque sein afin de reconstruire la bordure latérale du sein, de remettre l'implant en position et de corriger la plénitude axillaire, au besoin.

RÉSULTATS : Les 16 patientes (20 seins) ont reçu des lambeaux capsulaires latéraux pour assurer le repositionnement médian durable de l'implant pendant un suivi d'au moins six mois (plage de six à 60 mois). Huit patientes ont consulté après l'installation d'implants qui s'étaient déplacés et les autres se sont présentées après l'installation d'expanseurs tissulaires seulement. Chez les huit patientes qui présentaient une plénitude axillaire, l'élévation du lambeau capsulaire a permis d'accéder au contenu axillaire pour l'exciser (quatre cas) ou incorporer la graisse axillaire dans le lambeau afin d'éviter de palper l'implant latéral. Elles n'ont souffert d'aucune complication majeure, complication infectieuse, ni complication de la cicatrisation des plaies. Toutes les patientes ont obtenu des résultats satisfaisants et se sont dites très satisfaites de leurs seins reconstruits et du confort axillaire sur le plan esthétique et fonctionnel.

CONCLUSIONS : Selon l'expérience des auteurs, le lambeau capsulaire latéral est une technique simple, sécuritaire et fiable pour corriger la malposition latérale des implants mammaires, reconstruire la bordure mammaire latérale et corriger une plénitude axillaire indésirable lors de la reconstruction primaire ou révisée des implants mammaires, ce qui améliore l'esthétisme et l'équilibre du sein.

The upper inner quadrant of the breast is considered by patients to be most important following breast surgery, and defects in this region are more likely to be associated with poor patient satisfaction $(1,8,9)$. In contrast to dual-plane techniques of aesthetic breast augmentation, the sternal attachment of the pectoralis major is maintained in alloplastic breast reconstruction to preserve soft tissue coverage of the medial breast and to prevent hyperdynamic animation of submuscular implants after mastectomy (10). The sternal attachment prevents medial displacement of the implant without a lateral counterpart to prevent lateral displacement. However, to maximize aesthetic outcomes and reduce reoperation rates following breast reconstruction, harmony must be achieved between all subunits (11). 

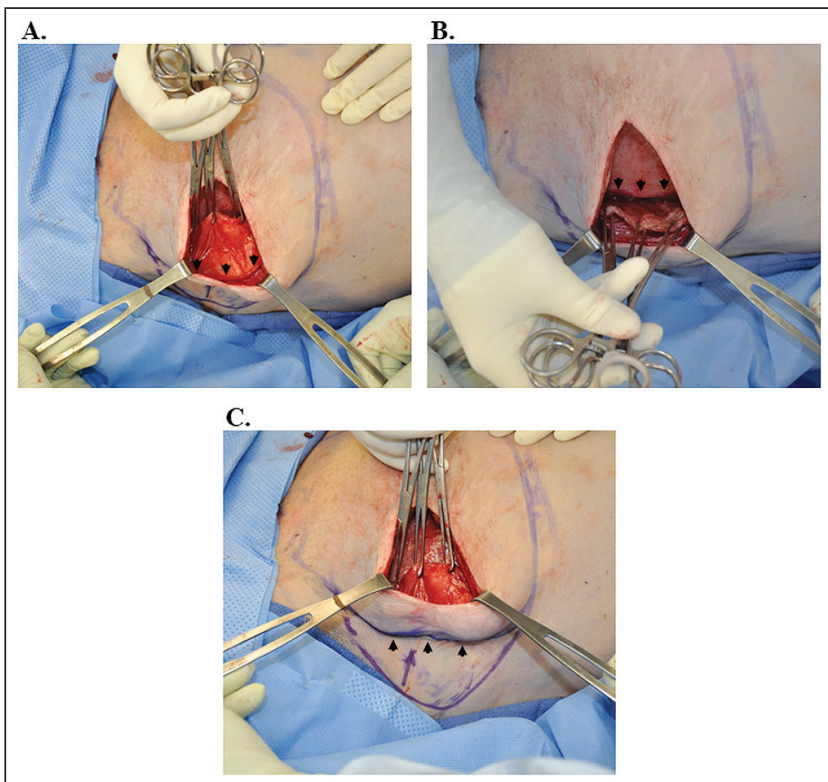

Figure 1): Intraoperative photographs of elevation of lateral capsular flap. A A lateral basilar capsulotomy was made and the lateral capsular flap has been elevated off of the chest wall from medial to lateral. Traction is provided with Allis clamps on the leading edge of the flap. The flap is anteriorly based and the flap base retracted laterally by the Army-Navy retractors. The flap pivot point is indicated by the black arrow heads. B Elevation of the lateral capsular flap gives access to the axillary contents that can be raised with the flap to provide lateral breast implant soft tissue coverage or excised to give definition to the lateral breast border. The Allis clamps remain on the flap leading edge, which has been retracted laterally for access to the lateral axillary contents. The axillary contents may be accessed lateral to the black arrowheads, which indicate the location of the lateral basal capsulotomy performed for flap elevation. C The lateral capsular flap dissection allows precise design of the lateral breast border as the shape of the breast border is the base of the flap. Medial traction is placed on the leading edge of the lateral capsular flap, which is held with Allis clamps. The redefined lateral breast border is indicated by the arrowheads in the photograph, which can be compared with the preoperative markings of the lateral breast border

The breast is bound laterally by the anterior axillary line, which serves as the transition from the lateral breast skin to the skin of the lateral chest wall and axilla $(9,12-14)$. The anterior axillary line is defined anatomically by the lateral border of the pectoralis major muscle as it proceeds from its origin to the chest wall. The lateral breast border has a concave silhouette transitioning to the convexity of the breast parenchyma and serves as an essential component to achieving an optimum result following reconstructive breast surgery. The lateral breast border can be blunted by unwanted axillary soft tissue in obese individuals, too sharp in slender patients without appropriate lateral soft tissue coverage, or malpositioned by poor implant selection, position or capsular contracture $(15,16)$. The development of novel surgical techniques is required to restore the loss of natural definition of the anterior axillary line and upper outer breast aesthetic subunit in prosthetic breast reconstruction or secondary breast augmentation.

A periprosthetic fibrous capsule is formed following alloplastic breast reconstruction or augmentation as a biological process initiated in response to insertion of a foreign body (17). The periprosthetic capsule is composed of dense network of collagen fibres surrounded by a rich vascular network (18). The histological architecture of the periprosthetic breast capsule with its sufficient intrinsic tensile strength and reliable vascular supply with attachments to the breast skin envelope and chest wall presents the surgeon with a reliable
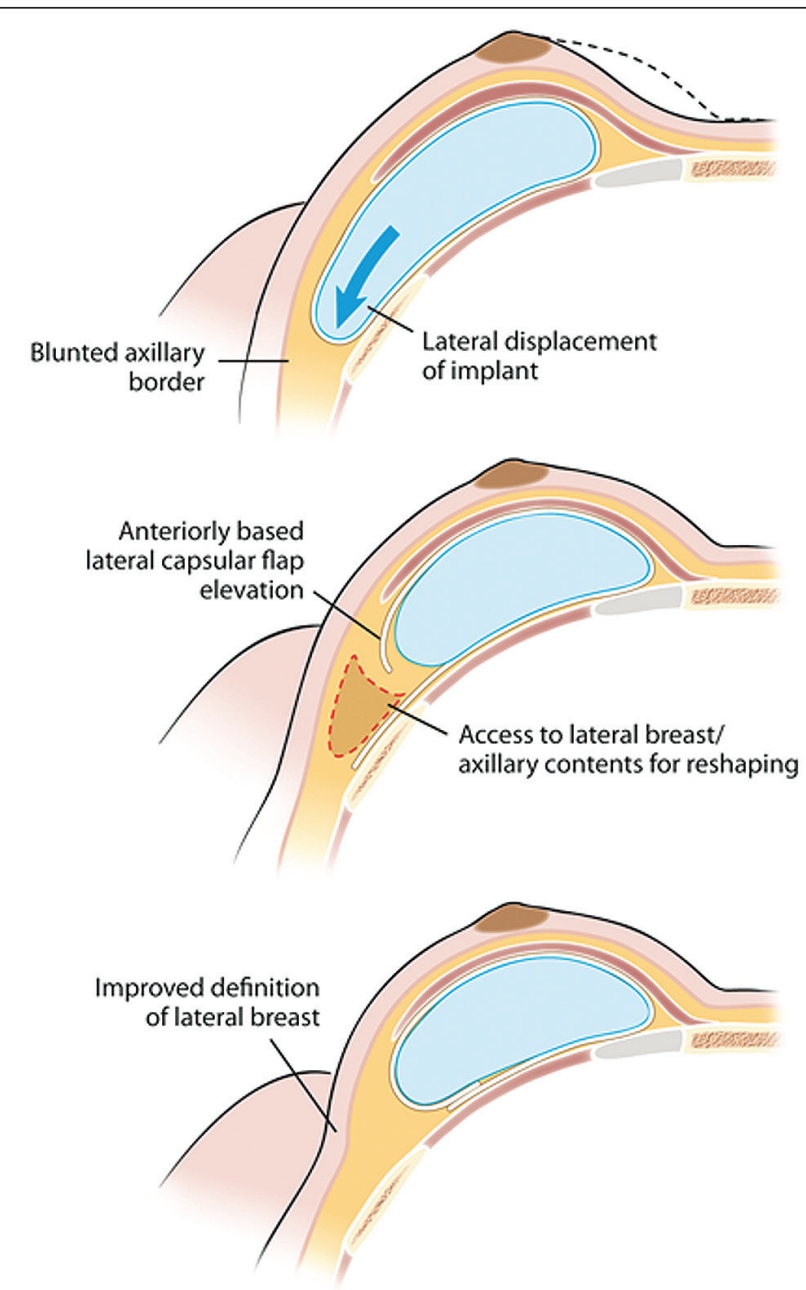

Figure 2) Illustration of elevation and inset of the lateral capsular flap. The patient is supine in the artist's rendition of flap elevation and inset. The capsulotomy is designed at the lateral edge of the base of the breast pocket. The anteriorly based lateral capsular flap is elevated either with soft tissue or to give access to axillary soft tissue for access when indicated. Buried twolayer suture closure is performed on the posterior aspect of the pocket to keep the suture line away from the lateral edge

material for adjunctive breast reconstruction $(15,19,20)$. The use of all or a component of the periprosthetic capsule as a capsular flap has been previously described for coverage of breast implant exposure, correction of contour deformities of the breast, management of visible or palpable periprosthetic wrinkling, reconstruction of the inframammary fold and correction of modification of implant position $(8,16,21$ 26). These reports have largely focused on utility of the capsular flap for reconstruction of the inframammary fold or lower pole of the breast; however, no previous reports have adequately addressed lateral implant malposition or contour deformities.

Herein, the authors introduce the use of a lateral capsular flap to restore the lateral breast border of eight consecutive patients. This technique has proved to be an effective and reliable method to define the contour of the lateral breast and to provide durable correction of implant malposition following alloplastic breast reconstruction.

Patient case review

\section{METHODS}

The study design was approved by the Institutional Review Board for Health Sciences Research at the University of Virginia (Charlottesville, Virginia, USA). For the present study, a prospectively maintained 
breast reconstruction database at the University of Virginia Medical Center between August 2010 and August 2015 was reviewed. A total of 118 implant-based breast reconstructions were identified during this period, and the lateral capsular flap was performed by the primary surgeon (CAC) to redefine the lateral breast border or correct implant position in 16 patients with at least six months of follow-up. Patient demographic data, operative indications - aesthetic or reconstructive, and postoperative outcomes data - including surgical site occurrences, postoperative antibiotic administration, hospital admissions and need for reoperation, were recorded.

\section{Surgical technique}

The patient is marked in the standing position to define the desired dimensions and location of the breast footprint including the upper medial and lateral breast borders and the inframammary fold. Use of the lateral capsular flap will redefine the lateral breast border and will redefine the volume of the breast pocket. It is important to plan the appropriate base width of device based on the amount of medialization expected in the lateral breast border and the anticipate breast base width following flap inset. Often, the authors plan for a $50 \mathrm{~mL}$ to $100 \mathrm{~mL}$ decrease in pocket volume depending on the degree of lateral capsular flap movement.

The periprosthetic capsule is approached through the previous mastectomy incision, and this technique has been used in patients who have previously undergone skin-sparing and nipple-sparing mastectomies. The tissue expander or breast implant device is removed to provide access to the periprosthetic capsule. Next, a wide anteriorly based lateral capsular flap is elevated in a plane superficial to the serratus fascia but deep to the well vascularized periprosthetic capsule (Figure 1A), giving access to the axillary soft tissue that can either be raised with the flap to give lateral implant coverage or can be excised to define the lateral breast border in obese individuals (Figure 1B). Flap elevation is tailored so that the base of the flap defines the shape of the lateral breast border (Figure 1C), and medial traction on the flap can provide a visual reference to the appearance of the new lateral breast border. A schematic representation of the surgical technique is presented in Figure 2, which illustrates the elevation and inset of the lateral capsular flap.

Following hemostasis, the flap is anchored to the chest wall posterior capsule in two layers with a deep layer of interrupted buried 2-0 PDS suture followed by a running buried 2-0 PDS suture. The suture line is posteriorly oriented to avoid sutures at the lateral edge of the breast pocket to prevent recurrence, which can often occur with lateral suture capsulorrhaphy alone. The preoperative anterior axillary line markings and resultant visual sharpness of the anterior axillary line serve as cues for the appropriate level of suture anchoring. One $15 \mathrm{Fr}$ round Blake drain is then placed. The implant is then positioned in the resultant pocket without disruption of the capsular flap. The incision is closed in layers. A supportive foam dressing is placed over the anterior axillary line followed by a surgical brassiere. The closed suction drains are maintained for a minimum of three days and the supportive foam dressing is maintained for one week.

\section{RESULTS}

A total of 16 patients (20 breasts) underwent lateral capsular flap from 2010 to 2015 for lateral implant malposition. Four of the patients also had unwanted axillary soft tissue excised after elevation of the capsular flap. The mean $( \pm$ SD) age was $59.8 \pm 3.4$ years and body mass index (BMI) was $28.6 \pm 2.0 \mathrm{~kg} / \mathrm{m}^{2}$. Two of the patients had been previously radiated. Eight patients required lateral capsular flap at the second stage expander to implant exchange, while eight patients presented for secondary reconstructive revision. All patients showed satisfactory durable results, with no history of wound healing disturbance or major complications. The follow-up in the present study ranged from a minimum of six months to five years. No patients have required reoperation for further definition of the anterior axillary line or upper outer quadrant breast aesthetic subunit.
Clinical case examples 1 and 2 include representative images of preoperative upper outer breast aesthetic subunit contour deformities and postoperative images of aesthetic improvement following lateral capsular flap in prosthetic reconstruction.

\section{Case example 1}

A 41-year-old woman with stage II right breast cancer with negative sentinel lymph node biopsy and a strong family history underwent bilateral skin-sparing mastectomy and staged tissue expander followed by $400 \mathrm{~mL}$ high-profile smooth round silicone implant breast reconstruction. She presented three months after surgery with descent and lateral malposition of the right breast implant (Figure 3).

A lateral and capsular flap was performed to correct lateral malposition of the right breast implant. An inferior capsular flap with reinforcing suture technique was performed to overcorrect the vertical discrepancy. Photographs at three and nine months after lateral and inferior capsular flaps are shown in Figures 4 and 5.

\section{Case example 2}

A 57 -year-old woman with a BMI $42 \mathrm{~kg} / \mathrm{m}^{2}$ presented seven years after bilateral breast reconstruction with staged expander and silicone implant reconstruction. Her left lateral malposition had been treated by the referring physician with suture capsulorrhaphy twice, followed by local serratus fascial flap and increasing implant projection with recurrence. At the time of presentation, her left breast contained a $650 \mathrm{~mL}$ high-profile silicone implant compared with her right breast with a $500 \mathrm{~mL}$ silicone moderate plus profile implant (Figure 6).

Lateral capsular flap with excision of axillary contents was performed to narrow the base width of the breast and to give definition to the lateral breast border after axillary soft tissue reduction (Figure 7 at three months). A lower projection smaller implant $(500 \mathrm{~mL}$ moderate plus silicone) was now appropriate after control of the lateral breast dimension was achieved.

\section{DISCUSSION}

With the medial border of the breast maintained by the pectoralis major insertion and the use of acellular dermal matrix to reproduce the inframammary fold after mastectomy, the lateral edge of the breast pocket is the least protected. Suture capsulorrhaphy and acellular dermal matrix slings have been described to reinforce the lateral breast border after lateral malposition; however, with high recurrence rates and increased cost, respectively. The use of capsular flaps has been described to reinforce the inframammary fold and shape the contours of the lower pole of the breast, but has not been described to reconstruct and define the lateral breast border.

The use of anatomical silicone implants, acellular dermal matrix and periprosthetic capsular-based operative techniques, including capsulotomy, capsulectomy and capsular flaps, have provided excellent tools in the armamentarium of the surgeon to restore an optimum aesthetic contour to the breast $(20,27,28)$. Even with these adjuncts, complications involving implant malposition, including both inferior and lateral displacement, continue to pose a major problem with unsatisfactory levels of recurrence or incomplete correction (15).

Capsule formation following prosthetic breast reconstruction or breast augmentation with silicone implants is a physiological process initiated in response to insertion of a foreign body. The periprosthetic capsule has been demonstrated to persist for as long as 17 years following the removal of a breast prosthesis (29). Utilization of all or a component of the breast capsule as a flap has been previously established as a durable adjunct for prosthetic breast reconstruction.

Furthermore, capsular flaps possess the ability to directly address breast skin envelope using autologous tissue. Capsular flaps can be used to redistribute soft tissue for addressing volumetric enhancement in contour deformities of the breast. Capsular flaps have been used as salvage procedures to address issues of inadequate overlying soft tissue coverage in instances of implant exposure, palpability, and rippling. Capsular flaps have the advantage of providing autologous tissue 


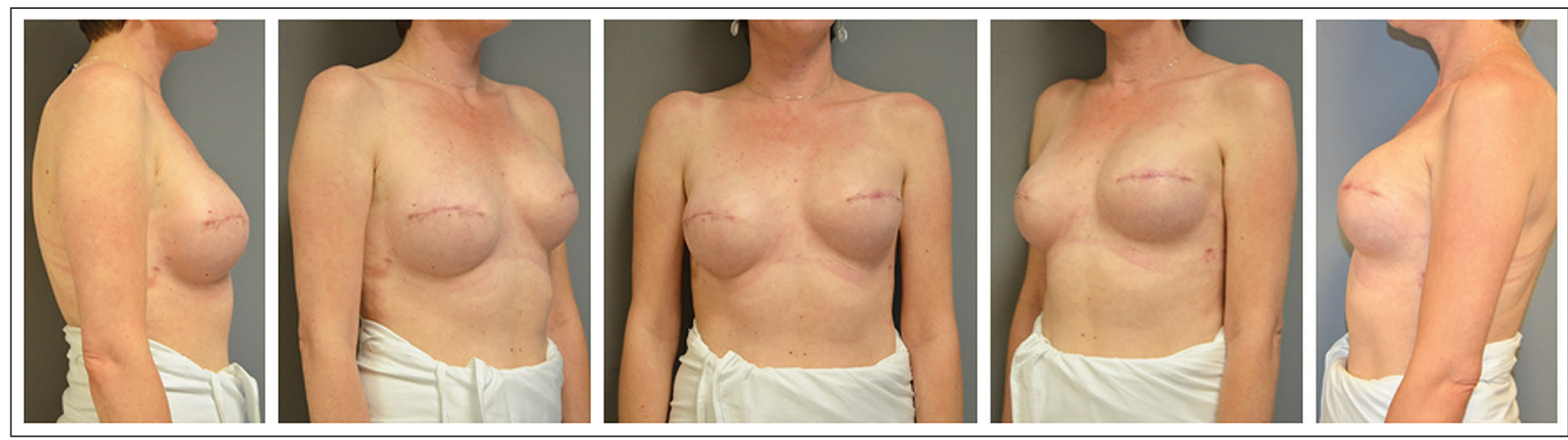

Figure 3) Case example 1: A 41-year-old woman after bilateral staged expander $400 \mathrm{~mL}$ high-profile implant breast reconstruction with lateral and inferior implant malposition

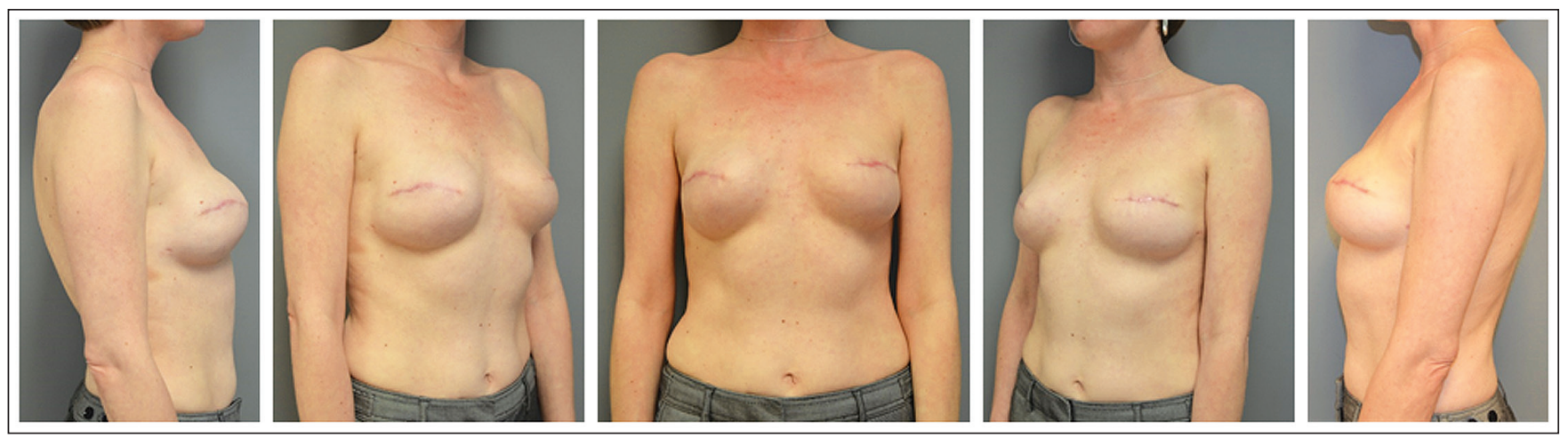

Figure 4) Case example 1: Three months after right lateral and inferior capsular flap restoration of appropriate implant position. Note the slight vertical overcorrection to allow for soft tissue elasticity. The inferolateral corner of the breast pocket will often have a mild soft tissue fold after combined inferior and lateral capsular flaps, which relaxes in time
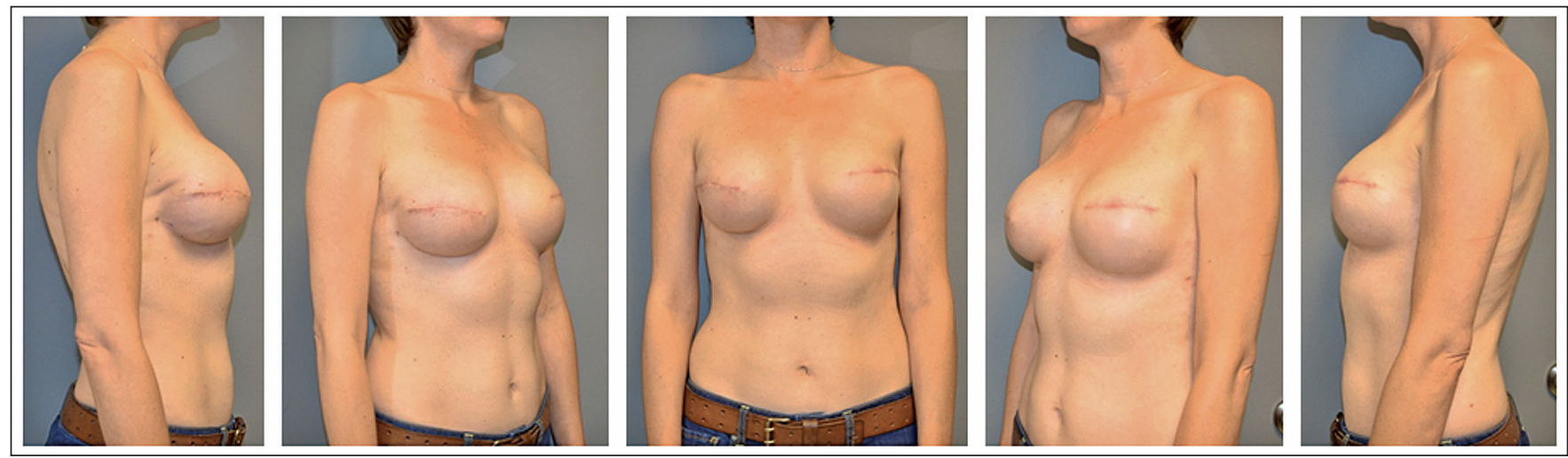

Figure 5) Case example 1: Nine months after right lateral and inferior capsular flap restoration of appropriate implant position. Implant position remains unchanged and symmetric. The mild inferolateral soft tissue fold after combined lateral and inferior capsular flap has resolved leaving an aesthetically pleasing lateral breast border

without requiring additional donor site morbidity, as in the case of other soft tissue fillers such as autologous fat. Tissue substitutes, such as acellular dermal matrices, can also provide additional soft tissue coverage without donor site morbidity; however, lack the rich vascular network of capsular tissue is associated with increased risk for infectious complications and are associated with greater operative costs. The indications for the use of the lateral capsular flap proposed in the present study are contour deformities of the lateral breast border or soft tissue deficiencies in the upper outer aesthetic subunit of the breast associated with previous breast augmentation or prosthetic breast reconstruction. The periprosthetic space and capsule are accessed through existing incisions, and do not require additional donor site morbidity. An advantage of this technique is that as the mastectomy skin flaps and capsular flaps are managed as distinct functional elements, the lateral capsular flap can be applied regardless of mastectomy incision. The elevation of the lateral capsular flap offers ample material to support the soft tissue envelope of the lateral breast, which is in the region with the highest propensity for implant palpability. In addition, in the obese patient at the time of flap elevation the lateral breast and axillary contents are exposed to allow for the excision of excess fat to further define the lateral breast border. An additional advantage of the lateral capsular flap is the opportunity to effectively narrow the base width of the breast footprint and as a consequence increase the projection for a given implant volume as demonstrated in the case presentations. Bengston et al (24) also described a lateral capsular flap for periprosthetic manipulation; however, this flap was 

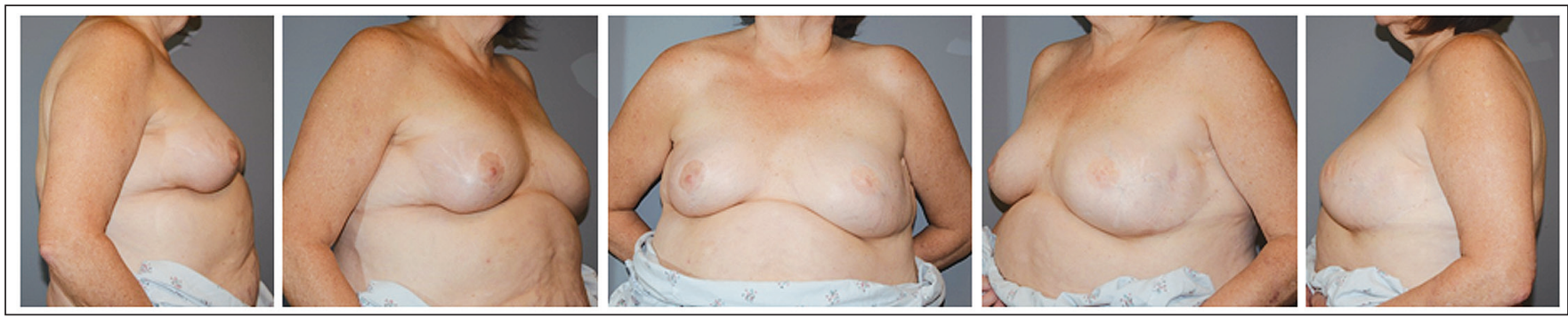

Figure 6) Case example 2: A 57-year-old woman with left breast lateral malposition and excess axillary soft tissue fullness. Several attempts at lateral suture capsulorrhaphy, fascial flap and higher profile implants had been attempted ( $650 \mathrm{~mL}$ high-profile silicone left breast implant)
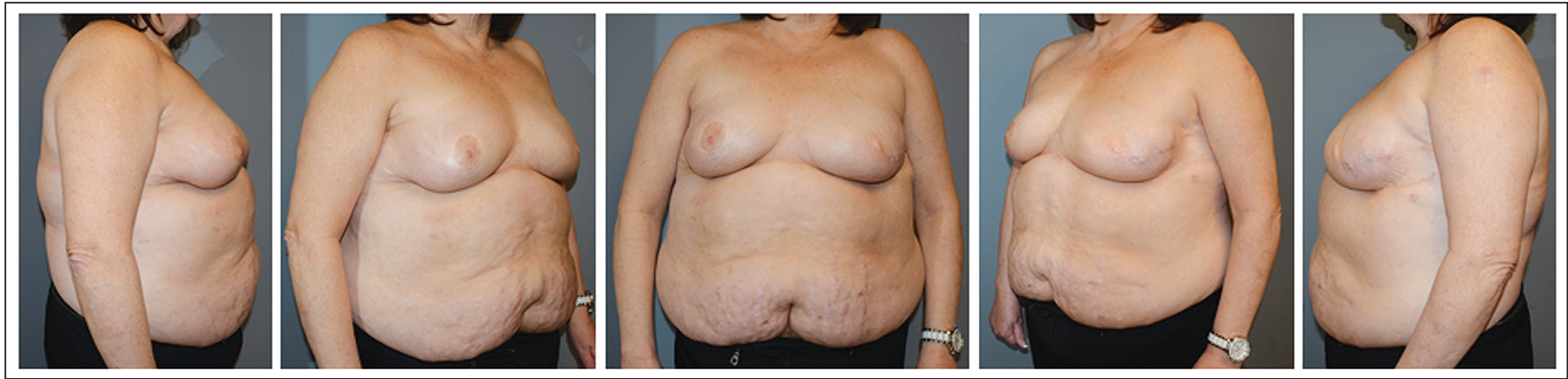

Figure 6) Case example 2: Three months after lateral capsular flap with excision of excess axillary soft tissue restores appropriate position of lateral breast border, gives definition to the lateral breast border and allows a smaller $500 \mathrm{~mL}$ moderate plus profile implant to be used to achieve appropriate symmetry

posteriorly based on the chest wall. The advantages of the anteriorly based lateral capsular flap described herein over existing capsular flap designs derive from the fact that the capsular flap is based anteriorly on the mobile breast periprosthetic capsule. This design element enables the surgeon to mobilize and precisely manipulate the lateral breast border under direct vision. The flap can then be secured to the posterior chest wall in two layers allowing for secure flap fixation to the chest wall periprosthetic capsule or fascia in a region that is not palpable by the patient.

In our hands, elevation and inset of the lateral capsular flap does not add significantly to the total procedural time and was not associated with additional patient discomfort or operative complications. Furthermore, the lateral capsular flap can be tailored intraoperatively to achieve the optimum aesthetic appearance of the lateral breast border and symmetry can be assessed with the patient supine to the contralateral breast. In our experience, relative contraindications to

\section{REFERENCES}

1. Bailey SH, Saint-Cyr M, Oni G, et al. Aesthetic subunit of the breast: an analysis of women's preference and clinical implications. Annals of plastic surgery 2012;68:240-5.

2. Pusic AL, Klassen AF, Snell L, et al. Measuring and managing patient expectations for breast reconstruction: Impact on quality of life and patient satisfaction. Exp Rev Pharmacoecon Outcomes Res 2012;12:149-58.

3. Roth RS, Lowery JC, Davis J, et al. Quality of life and affective distress in women seeking immediate versus delayed breast reconstruction after mastectomy for breast cancer. Plast Reconstr Surg 2005;116:993-1002.

4. Lee CN, Hultman CS, Sepucha K. Do patients and providers agree about the most important facts and goals for breast reconstruction decisions? Ann Plastic Surg 2010;64:563-6.

5. Lee CN, Hultman CS, Sepucha K. What are patients' goals and concerns about breast reconstruction after mastectomy? Ann Plast Surg 2010;64:567-9.

6. Wickman M. Breast reconstruction - past achievements, current status and future goals. Scand J Plast Reconstr Surg Hand Surg 1995;29:81-100.

7. Roth RS, Lowery JC, Davis J, et al. Psychological factors predict patient satisfaction with postmastectomy breast reconstruction. Plast Reconstr Surg 2007;119:2008-15. application of the lateral capsular flap for improvement in the lateral breast border are a history of previous breast radiation or a history of thin mastectomy flaps which are densely adherent to the underlying periprosthetic capsule without an underlying fat plane between the skin and capsule.

In our experience, the lateral capsular flap represents a simple, safe and reliable technique to reconstruct the lateral breast border in alloplastic reconstruction or revision of prior breast augmentation. With this method, the lateral border of the breast can be accurately repositioned to restore anesthetic contour to the upper outer quadrant aesthetic breast subunit and anterior axillary line with a single procedure.

DISCLOSURES: The authors have no financial disclosures or conflicts of interest to declare.

8. Coutinho M, Southern S, Ramakrishnan V, et al. The aesthetic implication of scar position in breast reconstruction. Br J Plast Surg 2001;54:326-30.

9. Spear SL, Davison SP. Aesthetic subunits of the breast. Plast Reconstr Surg 2003;112:440-7.

10. Madsen RJ Jr, Chim J, Ang B, et al. Variance in the origin of the pectoralis major muscle: Implications for implant-based breast reconstruction. Ann Plast Surg 2015;74:111-3.

11. Restifo RJ. The "aesthetic subunit" principle in late TRAM flap breast reconstruction. Ann Plast Surg 1999;42:235-9.

12. Ellis H, Colborn GL, Skandalakis JE. Surgical embryology and anatomy of the breast and its related anatomic structures. Surg Clin N Am 1993;73:611-32.

13. Morello DC, Christensen M, Hidalgo DA, et al. Breast asymmetry. Aesth Surg J 2003;23:472-9.

14. van Deventer PV, Page BJ, Graewe FR. Vascular anatomy of the breast and nipple-areola complex. Plast Reconstr Surg 2008;121:1860-1.

15. Spear SL, Little JWR. Breast capsulorrhaphy. Plast Reconstr Surg 1988;81:274-9.

16. Persichetti P, Langella M, Filoni A, et al. How to redefine the inframammary fold: The "slingshot" capsular flap. Ann Plast Surg 2013;70:636-8. 
17. Spear SL, Baker JL Jr. Classification of capsular contracture after prosthetic breast reconstruction. Plast Reconstr Surg 1995;96:1119-23.

18. Schuringa MC, Hartman EH, Ruhe PQ, et al. Formation of a reliable capsular flap in a rat model. J Plast Reconstr Aesth Surg 2007;60:536-42.

19. Chasan PE. Breast capsulorrhaphy revisited: A simple technique for complex problems. Plast Reconstr Surg 2005;115:296-301.

20. Chasan PE, Francis CS. Capsulorrhaphy for revisionary breast surgery. Aesth Surg J 2008;28:63-9.

21. Imran D, Javaid M, Lewis D, et al. Capsular flap for correction of contour deformities of the breast. Ann Plast Surg 2005;54:662-3.

22. Brandstetter M, Schoeller T, Pulzl P, et al. Capsular flap for coverage of an exposed implant after skin-sparing mastectomy and immediate breast reconstruction. J Plast Reconstr Aesth Surg 2010;63:1388-90.

23. Bogdanov-Berezovsky A, Silberstein E, Shoham Y, et al. Capsular flap: New applications. Aesth Plast Surg 2013;37:395-7.
24. Bengtson BP, Ringler SL, George ER, et al. Capsular tissue: A new local flap. Plast Reconstr Surg 1993;91:1073-9.

25. Gargano F, Moloney DM, Arnstein PM. Use of a capsular flap to prevent palpable wrinkling of implants. Br J Plastic Surg 2002;55:269.

26. Voice SD, Carlsen LN. Using a capsular flap to correct breast implant malposition. Aesth Surg J 2001;21:441-4.

27. Spear SL. Capsulotomy, capsulectomy, and implantectomy. Plast Reconstr Surg 1993;92:323-4.

28. Spear SL, Sher SR, Al-Attar A. Focus on technique: Supporting the soft-tissue envelope in breast reconstruction. Plast Reconstr Surg 2012;130:89S-94S.

29. Rockwell WB, Casey HD, Cheng CA. Breast capsule persistence after breast implant removal. Plast Reconstr Surg 1998;101:1085-8. 